\title{
Effect of Calcereous Cow Horn and Storage on the Physicochemical Properties of Cement-Bonded Particleboards from Groundnut Hulls
}

\author{
Ogunkunle Olaoluwa Ayobami, Olayoriju Solomon Laja, and Olajide Sunday Emmanuel
}

Department of Chemistry, Obafemi Awolowo University, Osun State, Ile-Ife, Nigeria

Correspondence should be addressed to Ogunkunle Olaoluwa Ayobami; skippoluv@yahoo.com

Received 1 July 2012; Accepted 15 November 2012

Academic Editor: Laura Pigani

Copyright (C) 2013 Ogunkunle Olaoluwa Ayobami et al. This is an open access article distributed under the Creative Commons Attribution License, which permits unrestricted use, distribution, and reproduction in any medium, provided the original work is properly cited.

\begin{abstract}
Fine particles of the groundnut hull and cow horn samples were prepared and subjected to hydration experiments with Portland cement with the moisture content maintained around 12\%. All the compatibility factor values were very well above $60 \%$ making the different combinations appropriate for particleboard production. Metal analyses suggested high concentrations of Ca in both samples with values of $62.68 \pm 0.47 \mathrm{wt} \%$ and $42.44 \pm 1.86 \mathrm{wt} \%$ for the cow horn and groundnut hull samples, respectively. Potassium was also present in high concentrations but was lower than that of calcium. The cow horn was found to be a good substitute for the synthetic $\mathrm{CaCl}_{2}$ additives. Combinations of $\mathrm{FeCl}_{3}$ with the cow horn gave better compatibility $\left(C_{A}\right)$ between the groundnut hull particles and the Portland cement due to chelation, with the hot-water-treated samples being the best. Bond formation was established through the hydroxyl $(-\mathrm{OH})$, carbonyl $(\mathrm{C}=\mathrm{O})$, esters or ethers $(\mathrm{C}-\mathrm{O})$, and amide $(\mathrm{N}-\mathrm{H})$ functional groups on the groundnut hall samples. Storage over a period of time also gave a better compatibility of the groundnut hull sample with cement even in the absence of hot-water pretreatments and chemical additives.
\end{abstract}

\section{Introduction}

Over the years, the use of wood-based products has been on the increase coupled with the need for low-cost building materials, household facilities, and production of cooking fuel that meet all health requirements. These have been attributed to the ever growing world population which has led to rapid deforestation [1]. The need for cheap, nonwooddependent alternatives was an immediate remedy for this problem and a potential to assist in satisfying the need for wood was found in agricultural residue fibres such as those of the groundnut hulls $[2,3]$. The benefits of utilizing agricultural residues for wood composite panels include developing a value-added product from a fibre source that is currently not well utilized as well as decreasing the demand for wood fibre.

Agricultural residues, considered to be wastes because they are not properly managed (utilized and disposed) thus causing more harm and having adverse effects on the environment [4], fulfill the purpose of the production of high-performance cement-bonded particleboards utilized as cheap building materials. These residues, in combination with cement, an inorganic binder, have been used in the production of valuable panels used in the construction of schools and residential homes in many countries [5]. However, lignocellulosic agricultural residues often contain chemical substances such as sugars and wood extractives which are polyphenolic in nature and inhibit cement hydration (hardening and setting), thereby inhibiting or entirely obstructing the cement crystalline formation for strength development [6].

Chemical substances also known as enhancers or additives are usually added to ameliorate the effects of the polyphenolic inhibitory chemical substances present in the agricultural residue but can have an adverse effect if in excess thus leading to the leaching of such substances [7].

These additives, when in excess, have been found to get leached from the particleboards when exposed to water for a relatively long time thus releasing their components, mostly metals, into the environment or directly onto the 
any species around it, accumulation of which could lead to poisoning or the toxicity by such metals. This has been attributed to their purer states and higher solubility in water which is responsible for their higher ionization in water resulting in their ease of release [8]. On the contrary, a more natural and stable renewable resource containing a high calcium content such as the cow horn which when leached will have little or no negative implications on the environment, will give a competitive performance, and is readily available was considered. In an effort to further reduce their cost and make them accessible, components such as the chemical additives can be replaced by these cheaper and available natural substitutes that will perform at par with their synthetic counterparts. This is part of the efforts being put into preserving the healthy characteristics of the cementbonded particleboards.

In this work the effect of calcium chloride, $\left(\mathrm{CaCl}_{2}\right)$ known to be the commonly used accelerator or enhancer in hydration experiment used for the purpose of ameliorating the effect of these polyphenolic phytochemical substances, was compared with that of the high calcium content cow horn used as a natural replacement for its synthetic counterpart. The chelate forming ability transition metal was exploited in the study by using a combination of the cow horn with iron (III) chloride at various ratios with the aim of reducing the quantity of synthetic chemical substances. In addition, the effect of storage over period of time was also investigated.

It is also worthy of note that there are other various techniques that can be employed other than the compatibility test to ascertain the possibilities of lignocellulosic species being appropriate as a raw material for particleboard production. Some of the other processes being utilized include the determination of the $\mathrm{pH}$ of the lignocellulosic species to be used with cement. Species whose $\mathrm{pHs}$ fall between 3.9 and 4.9 will be suitable, but those whose $\mathrm{pHs}$ are less than 3.9 are the most suitable. Any species whose $\mathrm{pH}$ value is above this limit will not be appropriate for use [9]. Likewise the percentage content of the soluble extractives in the lignocellulosic species must not be greater than $7 \%$ if it is to be appropriate for particle board production [10]. The particle size of the lignocellulosic material is also a measure of compatible mixing where it was observed that the inhibition of the cement setting increases with increasing fineness of the particles [11]. One of the most recent is the Differential Scanning Calorimetry (DSC) based on the heat released during the hydration reactions. It is very sensitive to temperature changes during hydration, and it has the ability to provide the instantaneous flux of free heat and the total energy of the hydration reaction $[12,13]$.

\section{Experimental}

The fresh bones (cow horns) used in this study were obtained from an abattoir located in Dada Estate Area, Osogbo, Osun State, Nigeria, while the groundnut hulls (Arachis hypogaea L.) were collected from Bodija Market located in Ibadan, Oyo State, Nigeria. The Portland cement was obtained from the Ewekoro Portland cement factory in Ogun State, Nigeria. It was ensured that the packaging was not been tampered with.
The hoofs (external cover) of the horns were removed before soaking the bony part in water for about 24 hours and washed free of blood. Solidified blood left in the porous part of the horns was removed with metallic sponge and metal rods. They were cut into smaller chips and rewashed in hot water before sun-drying them for about two weeks.

On collecting the fresh groundnuts, the seeds and other unwanted materials in the samples were separated from the hulls, before being sun-dried. The dried groundnut hulls and the cow horns were hammer-milled and sieved into particles of various sizes namely the $0.60 \mathrm{~mm}, 0.85 \mathrm{~mm}, 2.00 \mathrm{~mm}$, and the fine particle sizes. The groundnut hull particles were then stored in a cool and dry place. A previously prepared groundnut hull particle samples that had been stored for three years were also sun-dried and observed to ensure that the moisture content was within the required range.

2.1. Proximate Analysis. The proximate analysis was carried out on the sample particles using the recommended methodologies of the Association of Official Analytical Chemists [14]. The parameters determined include moisture content, crude fibre, crude protein, ash content, and ether extract.

2.2. Metal Analysis. The hammer-milled groundnut hull and cow horn particles were analysed for their metal contents using Energy Dispersive X-ray Fluorescence (EDXRF) spectrometer, at the Centre for Energy Research and Development, Obafemi Awolowo University, Ile-Ife, Nigeria.

2.3. Hot-Water Treatment of the Sample. Some of the groundnut hull sample was pretreated through heating using a thermostated water bath at $80^{\circ} \mathrm{C}$ in hot deionised water for about one hour after which the sample was sieved and resoaked in warm deionised water and later in cold water for about 10 minutes before being air-dried until it attained a moisture content of about $12 \%$. The solution extract was collected, suction-dried, and used for phytochemical screening.

This was done to substantially reduce the concentrations of the water-soluble extractives and other phytochemical substances in the sample.

2.4. Phytochemical Screening. Hot-water extract of the groundnut hull sample was subjected to phytochemical screening to ascertain the chemical substances (considered to be inhibitory in nature) present in them [15]. Alkaloids anthraquinone, reducing sugar, glycosides, saponins, tannins, and flavonoids were all tested for in the sample.

2.5. Compatibility Test. This was carried out in form of hydration test to determine the level of the compatibility of cement with the lignocellulosic materials. It was also carried out with the aid of calcium chloride and iron (III) chloride which were synthetic chemical accelerators while the cow horn particles served as the natural accelerator at different ratios. This was done based on a method developed by the Wood Composite Branch of Forestry Research Institute, Malaysia (FRIM). The compatibility measurements were carried out using the AreaRatio method [9] in the hydration test kit. 
2.6. Hydration Experiment for Neat Cement. The hydration tests were performed in a hydration set which comprised of the Dewar flask embedded in an insulated system. About $90 \mathrm{~cm}^{3}$ of deionised water was added to $200 \mathrm{~g}$ of neat cement in a plastic bag. The resulting mixture was properly agitated until an homogenous paste was formed before a data logger was attached which recorded the temperature changes at an interval of 15 minutes after being properly sealed and properly insulated in the Dewar flasks within the hydration test kits. The average room temperature was also noted before and after each experiment. This experiment was carried out in triplicate, after which a plot of temperature $\left({ }^{\circ} \mathrm{C}\right)$ against time (hour) was made. The volume of deionised water used for subsequent experiments involving lignocellulosic material was obtained using the expression

$$
\text { volume of water }=90+15\left(0.3-\frac{\mathrm{MC}}{100}\right),
$$

MC: Moisture content which was maintained at approximately $12 \%$.

\subsection{Hydration Experiment for Cement-Sample Mixture.} Hydration temperature experiment was also carried out on the cement-sample mixture to determine the compatibility of the lignocellulosic sample with cement binder. A samplecement ratio of $15: 200$ was employed. It involved the mixing of about $15 \mathrm{~g}$ of sample and $200 \mathrm{~g}$ of cement in a plastic bag. They were properly mixed in the dry state before a calculated amount of deionised water obtained using the expression in (1) was added. The mixture was then properly mixed with the water until homogeneity was achieved. It was noted that there was a slight rise in temperature. The mixture was quickly placed inside the Dewar flask, and the data logger was inserted to measure the temperature changes at a predetermined interval for 24 hours after it had been properly insulated in the hydration test kit. Three replications of this experiment were carried out. For each of the experiment, a plot of hydration temperatures $\left({ }^{\circ} \mathrm{C}\right)$ against time (hour) was made, and it was compared with the one obtained for neat cement using Area-Ratio method.

The compatibility factor $C_{A}$ was obtained from the hydration experiment using the expression below

$$
C_{A}=\left(\frac{A_{\mathrm{wc}}}{A_{\mathrm{nc}}}\right) \times 100,
$$

where $A_{\mathrm{wc}}$ : area under the hydration heating curve of samplecement-water mixture; $A_{\mathrm{nc}}$ : area under the hydration heating rate curve of neat cement-water mixture. $C_{A}$ is expressed in percentage (\%) [16].

2.8. Addition of Chemical Additives. To ensure proper mixing with the sample-cement mixture, the chemical additives were first dissolved in a little amount of deionised water, enough to dissolve the chemical additive completely, before making it up to the calculated volume obtained (using (1)), which was the amount of water required for the hydration experiment. This solution was then added to the sample-cement mixture that had been properly mixed.
The chemical additives used for this experiment were iron (III) chloride $\left(\mathrm{FeCl}_{3} \cdot 6 \mathrm{H}_{2} \mathrm{O}\right)$, calcium chloride $\left(\mathrm{CaCl}_{2}\right)$, and the cow horn which is a rich natural source of calcium.

A modification was employed in the case of the cow horn due to its insolubility in water. It was added to the samplecement mixture before the addition of the required amount of water. The amount of additives used in the compatibility experiments was based on the weight of cement used.

2.9. Sample Preparation for Infrared Analysis. The cured composites obtained from the compatibility hydration test experiments were dried, crushed into powdery form, and kept in different labeled sample bottles. They were subjected to infrared spectrophotometric analysis, using FT-IR system, spectrum BX model, at the Central Science Research Laboratory, the University of Ibadan, Nigeria.

\section{Results and Discussion}

The results of this study are discussed under the following subtopics.

3.1. Availability of Sample. The groundnut hulls which are considered to be waste, was found to be about $28.5 \%$ of the whole fruit. This low value was attributed to the size of the seed which makes up the majority of the fruit. The edibility and its high economic value of the seed resulted in the constant cultivation which makes the hulls readily available. The physical properties of the samples used showed that the groundnut hull is a solid and brownish in colour while the bone was obtained as white solid. The starting groundnut hull sample was light brown but turned dark brown when treated with hot water. This was attributed to the slight oxidation process; it went through due to the increase in temperature. Fine particle sizes of the two samples (groundnut hull and bone) are used throughout the study.

3.2. Proximate Analysis. The analysis showed that the cow horn sample gave values of $5.96 \pm 0.48,53.96 \pm 1.04,39.87 \pm$ 0.98 , and $0.48 \pm 0.29 \%$, respectively, for the moisture, ash, crude protein, and ether extract contents while the groundnut hull sample gave $10.24 \pm 0.88,6.95 \pm 1.01,0.90 \pm 0.29,27.12 \pm$ $1.10,10.07 \pm 0.87$, and $44.72 \pm 0.99 \%$ for moisture, ash, free fat, crude fibre, crude protein, and nitrogen-free extract contents, respectively. After periodical determinations of moisture content on the lignocellulosic sample, using the conventional method [14], it was observed that the percentage moisture in the sample was approximately $6 \%$. This made the sample very suitable for this study because it was not up to the marginal $12 \%$ standard used in such studies and productions prior to use. It would also be able to withstand the addition or absorption of more moisture in as much as it is not more than the stipulated $[6,17,18]$. Ash content also known as the mineral content had the highest value while the ether extract that determined the fat, oil, and lipid contents of the sample had the lowest value. Crude protein content of approximately $40 \pm 0.98 \%$ was obtained which indicated the presence of nitrogenous compounds (amino acids) and fibres in the form 
of collagen and keratin [19]. This is expected to further enhance bond formations which translate to a corresponding increase in strength of the composites made from the sample. This can be attributed to the presence of lone pairs of electrons on the nitrogen atoms in the amino groups of the amino acids which in turn form bonds with the electrophiles present in the form of metals in their various stable oxidation states. In the groundnut hull sample, carbohydrate had the highest value, followed by crude protein. These two values account for the lignin and cellulose content of the sample which makes the sample a substitute for wood. The moisture content of $10.24 \pm 0.88 \%$ is ideal for hydration experiment.

3.3. Phytochemical Screening. Various phytochemical substances were detected in the hot-water extract of the groundnut hull samples. Flavonoids, glycosides, alkaloids, sterol, and sugar were present in high quantities confirming the polyphenolic and nitrogenous nature of these inhibitory substances [9] while anthraquinone and saponins were absent. This indicated that quite a substantial amount of these substances were removed through hot-water-extraction process [20].

3.4. Metal Analysis. The metal analysis for the two samples showed very high concentrations of calcium for both samples. The highest value of $62.68 \pm 0.47 \mathrm{wt} \%$ was obtained for the cow horn as while the groundnut hull had $42.44 \pm$ $1.86 \mathrm{wt} \%$. Potassium also had high values in two samples but was lower to those of calcium. The high concentration value of calcium in the cow horn can be attributable to the nature of the sample and its location in the body of animal. Since all the main compounds present in the Portland cement used for this study contained calcium [21], addition of the bone sample as chemical additive will further increase the concentration of the metal, hence more cations became available for coordination and bond formation. All the other metals present in both samples were transition elements, although they were all in a relatively low concentration. Their roles became prominent due to the presence of incompletely filled d-orbitals responsible for chelate formation; they also enhanced coordination in the sample-cement composite. Metals play a major role in bond formation in the boards, which usually results in higher and better mechanical properties [22]. Groundnut hull analysis showed that potassium has the highest concentration in the groundnut hull followed by calcium, and chromium has the lowest concentration. The concentrations of $\mathrm{K}, \mathrm{Ca}$, and $\mathrm{Fe}$ agreed with those reported by Ogunkunle [23]. $\mathrm{Ca}, \mathrm{K}, \mathrm{Mn}, \mathrm{Fe}, \mathrm{Cu}$, and $\mathrm{Zn}$ are present in both samples, adding cow horn to groundnut hull as additive will further increase the concentration of these metals in the composite, hence leading to more bond formation.

3.5. Effect of Storage. Compatibility factor $\left(C_{A}\right)$ values of $60.55 \pm 1.21 \%$ and $96.63 \pm 1.20 \%$ for the untreated and hotwater-treated groundnut hull samples, respectively, without additives were obtained when the stored groundnut hull sample was freshly prepared about three years earlier [23]. These values were low compared to the $95.83 \pm 1.34 \%$ and

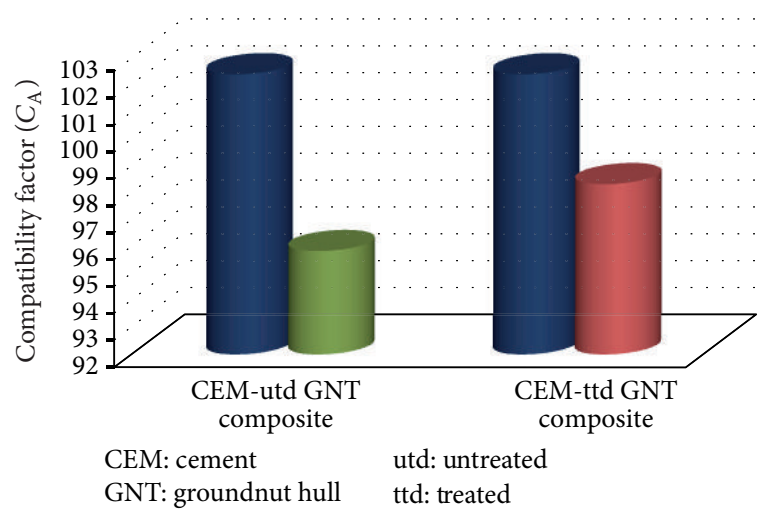

FIGURE 1: Effect of storage on compatibility factors of untreated and hot-water-treated samples with cement.

$98.29 \pm 0.97 \%$ obtained for the untreated and hot-watertreated of the stored sample, respectively, (Figure 1). This was attributed to the disintegration of the sugars present in the sample as an inhibitory agent, thus enhancing the compatibility of the cement binder with the groundnut hull sample [24], thus indicating that proper storage can increase the compatibility of lignocellulosic samples with cement leading to the production of stronger and better particleboards.

3.6. Compatibility Test. The compatibility factors $\left(C_{A}\right)$ obtained from the hydration temperature experiments using the untreated and hot-water treated samples without and with $2 \%$ of $\mathrm{CaCl}_{2}$ as additive. Figure 2 showed that there was a better compatibility between the cement and the groundnut hull samples in the presence of $2 \% \mathrm{CaCl}_{2}$ based on the weight of cement. An average $C_{A}$ value of $102.33 \pm 1.26 \%$ was obtained with $\mathrm{CaCl}_{2}$ and $95.83 \pm 1.21 \%$ without $\mathrm{CaCl}_{2}$. Masking of active sites of the inhibitory substances by calcium was responsible because during the hydration, calcium ions attacked their active functional groups (mainly the hydroxyl and carbonyl) of some of these phytochemical substances hence reducing their inhibitory effect on cement setting and hardening [25]. A corresponding increase in the peak temperature at a reduced time was also observed.

A better $C_{A}$ value was obtained with the hot-water treated samples, for those with $\mathrm{CaCl}_{2}$ and without [26]. This was attributed to the removal of some inhibitory phytochemical substances through the hot-water extraction and a further masking of the active sites which rendered them inert thus reducing their interference in the setting of cement with the groundnut hull samples [20].

On replacing the $\mathrm{CaCl}_{2}$ additive with cow horn, a change in the trend in the $C_{A}$ values was observed. Slightly lower values of $C_{A}$ were obtained with the value of $91.35 \pm 1.31 \%$ arising from the $3 \%$ cow horn additive. The $C_{A}$ values obtained were well above the proposed value of $60 \%$ by [9] as being very appropriate for particleboard production. More quantity of the cheap and readily available cow horn will be required. Better $C_{A}$ values were obtained with hot-water treated samples also presented in Figure 3. The cow horn being a natural source of calcium then solves the problem 


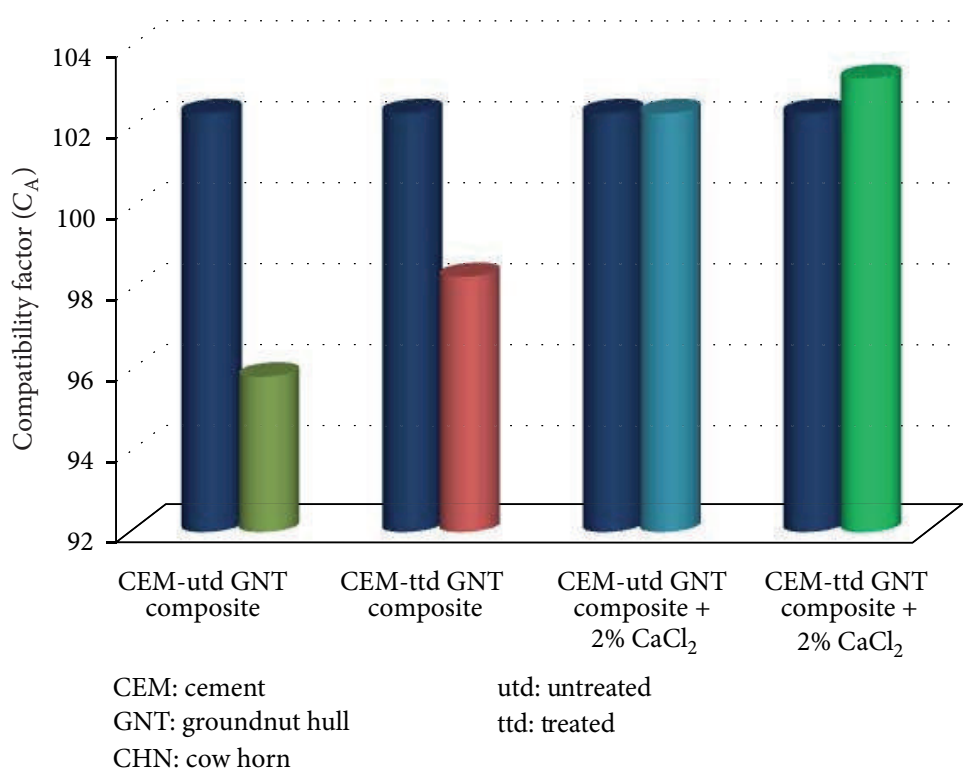

FIGURE 2: Compatibility factors of untreated and hot-water -treated samples with $2 \% \mathrm{CaCl}_{2}$.

of the gradual leaching of the chemical substances used as accelerators in the setting of cement with lignocellulosic materials.

These values indicated that the cow horn sample can be used as a good and cheap replacement for chemical additives that acts as enhancers in the setting of cement with the lignocellulosic sample. The values and the peak temperature obtained were lower than those obtained when pure $\mathrm{CaCl}_{2}$ was used. This was attributed to the impure nature of the calcium present in the horn which will definitely affect its potency (Figure 3). It is also obvious that the hot-water treated sample performed better with or without the pure $\mathrm{CaCl}_{2}$. Better alignments of the plots resulting in higher $C_{A}$ values were observed with the hot-water treated sample which further suggested that some polyphenolic inhibitory substances that usually disturb the setting of the cement which must have been highly reduced by the treatment [26]. Higher $C_{A}$ value translates to better compatibility between the lignocellulosic species and cement which also translates to better stability and strength in the board produced using such residues.

The groundnut hull-cow horn ratio of $15: 7.5$ gave better compatibility values $\left(C_{A}\right)$ of $101.16 \pm 2.14 \%$ and $96.22 \pm 0.73 \%$ for untreated and hot-water treated samples, respectively, (Figure 4). The hot-water treated sample-cow horn mixtures were observed to attain their peak temperature earlier when compared with the untreated ones. This may also be due to the reduction in the polyphenolic phytochemical setting inhibitory substances after hot-water treatment [27].

The result showed that cow horn (without additives) is ideal for the production of the cement-bonded particle board. The bone-cement mixture attained the peak temperature of $55^{\circ} \mathrm{C}$ with $C_{A}$ value of $99.38 \pm 1.01 \%$ after just 7.5 hours, and on the other hand, when groundnut hull was mixed with the cow horn, the peak temperatures were not attained until about 12-14 hours later. This outstanding performance of the cow horn may be due to its high percentage of the crude protein content. Protein is a polyamide containing amino and carboxylic functional group through which they can form bonds with the ions in the cement. The higher the number of bonds formed, the more the strength of the composite. The presence of keratin and collagen also contribute to the strength of the bone-cement composite [19].

Figure 5 described the compatibility test result obtained when various ratios of $\mathrm{FeCl}_{3}$ and cow horn were used as chemical additives; all the cow horn- $\mathrm{FeCl}_{3}$ ratios considered (Figure 5) gave $C_{A}$ values greater than $60 \%$, hence they are suitable for particle board production [9].

The cow horn- $\mathrm{FeCl}_{3}$ ratio of $1: 2$ gave better hydration value of $95.77 \pm 1.33 \%$ and $99.07 \pm 0.87 \%$ for untreated and hot-water treated samples of the same particle sizes, respectively. This could be attributed to the presence of $\mathrm{Fe}^{3+}$ ion $\left(\mathrm{d}^{5}\right)$ which has the ability to form chelates, thus forming several bonds due to the unfilled or available d-orbitals that are usually involved in bond formation [7]. These bonds are formed with the active sites of the inhibitory phytochemical substances thus making them inert [20]. This gave room for the cement to bind with the groundnut hull particles with a lower setting time [28]. In both cases, addition of not more than $3 \%$ of the additives gave the best results [29].

The presence of other metals in the samples, though in limited amounts, also enhanced the bonding processes between the binder and the groundnut hulls [7], thus resulting in a higher $C_{A}$. The peak temperature increased while it took lesser time to reach these temperatures when compared to the situation when $\mathrm{FeCl}_{3}$ was absent. This suggested the possibility of better coordination in the presence of $\mathrm{Fe}^{3+}$ ions.

3.7. Infrared Spectroscopy. In this study, infrared analysis was used to establish bond formation between the sample particle cement and chemical additives and to also ascertain that the cured composites from the hydration tests were not the same 


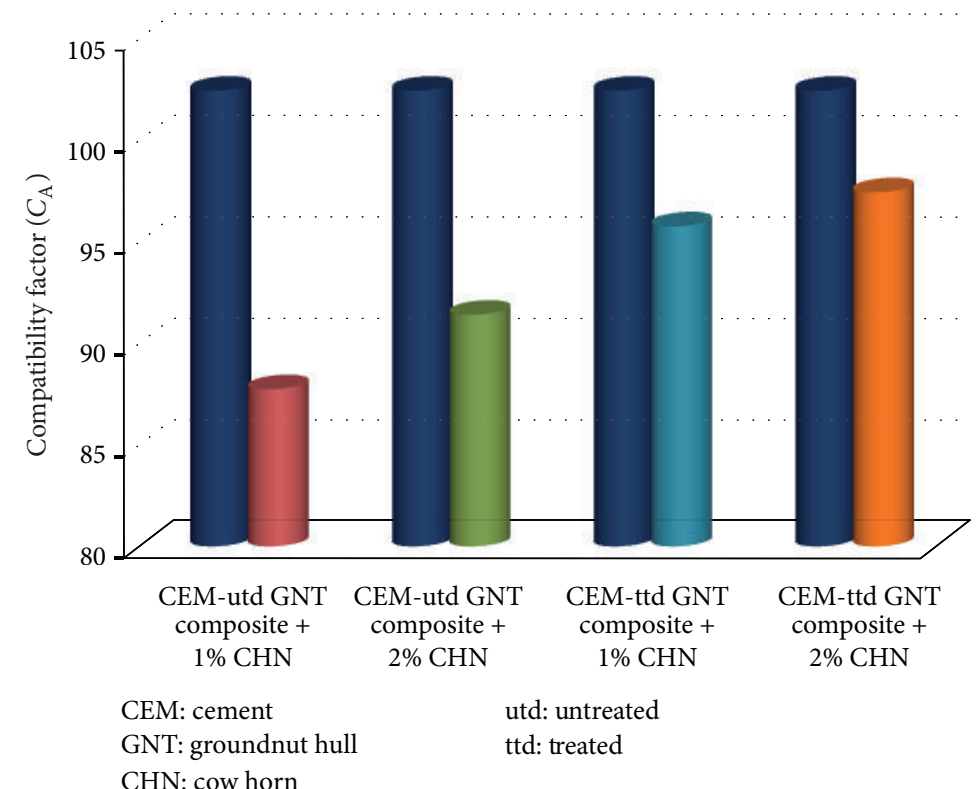

FIGURE 3: Compatibility factors of untreated and hot-water-treated samples with varying quantities of cow horn additive.

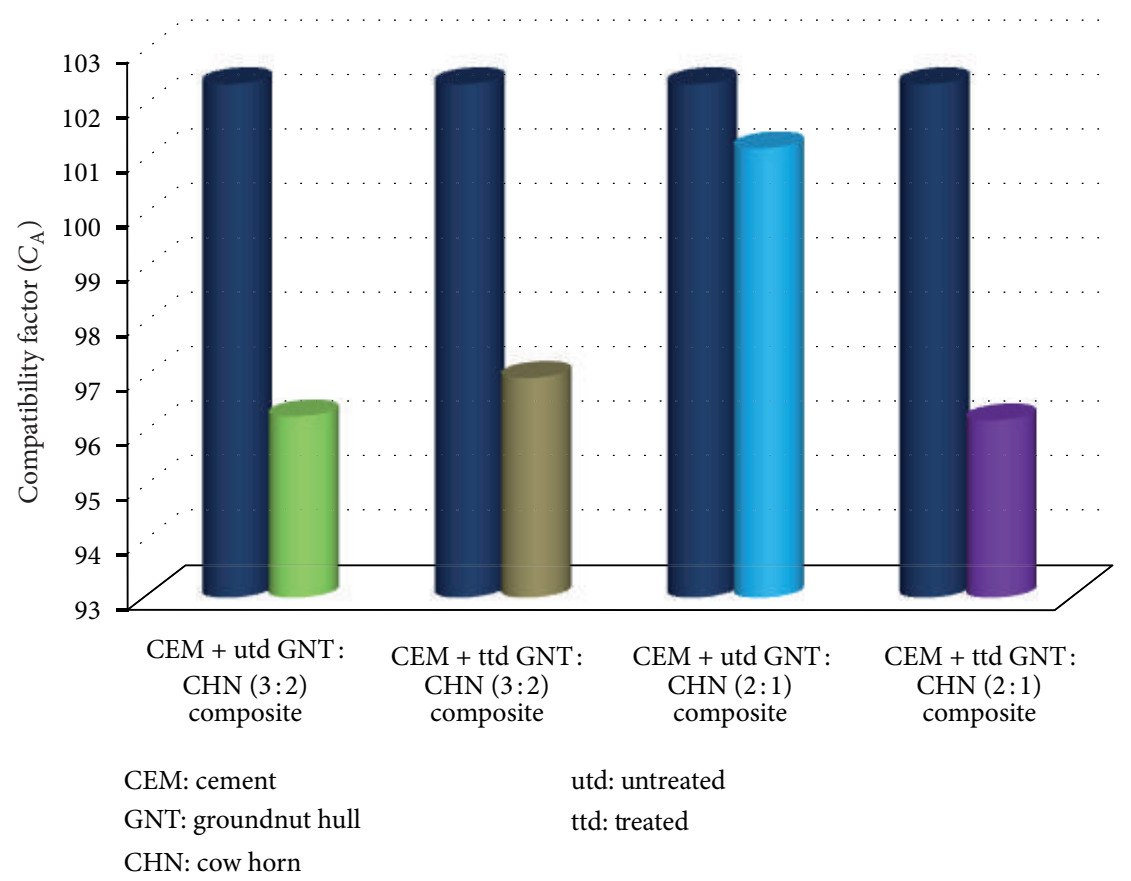

FIGURE 4: Effect of various ratios of cow horn particles and groundnut hull sample on the compatibility factor.

as the starting materials. The infrared bands on the cow horn and the groundnut hull samples were compared with the bands of their respective composites with and without the synthetic chemical additives. The absorption band showed a lower band shift that was observed at $1656 \mathrm{~cm}^{-1}$ for the cow horn and $1650 \mathrm{~cm}^{-1}, 1635 \mathrm{~cm}^{-1}$, and $1653 \mathrm{~cm}^{-1}$ respectively for the cow horn-cement mixture, hot-water treated groundnut-cow horn $(15: 10)$ and untreated groundnut-cow horn $(15: 7.5)$ respectively, which indicated bond formation through the carbonyl group. Similar trend was observed in a band tentatively assigned to the $\mathrm{C}-\mathrm{O}$ ether functional group where the absorption frequency moved from $1239 \mathrm{~cm}^{-1}$ for the cow horn to $1113 \mathrm{~cm}^{-1}, 1125.92 \mathrm{~cm}^{-1}, 1135 \mathrm{~cm}^{-1}$, and $1012 \mathrm{~cm}^{-1}$, respectively, for the cow horn-cement mixture, hot-water treated groundnut-cow horn $(15: 10)$, treated groundnut-cow horn $(15: 7.5)$, and untreated groundnutcow horn $(7.5: 7.5)$, respectively. The absence of some of these bands in hot-water sample was attributed to the loss of these tentatively assigned functional groups in the pretreating hotwater extraction. 


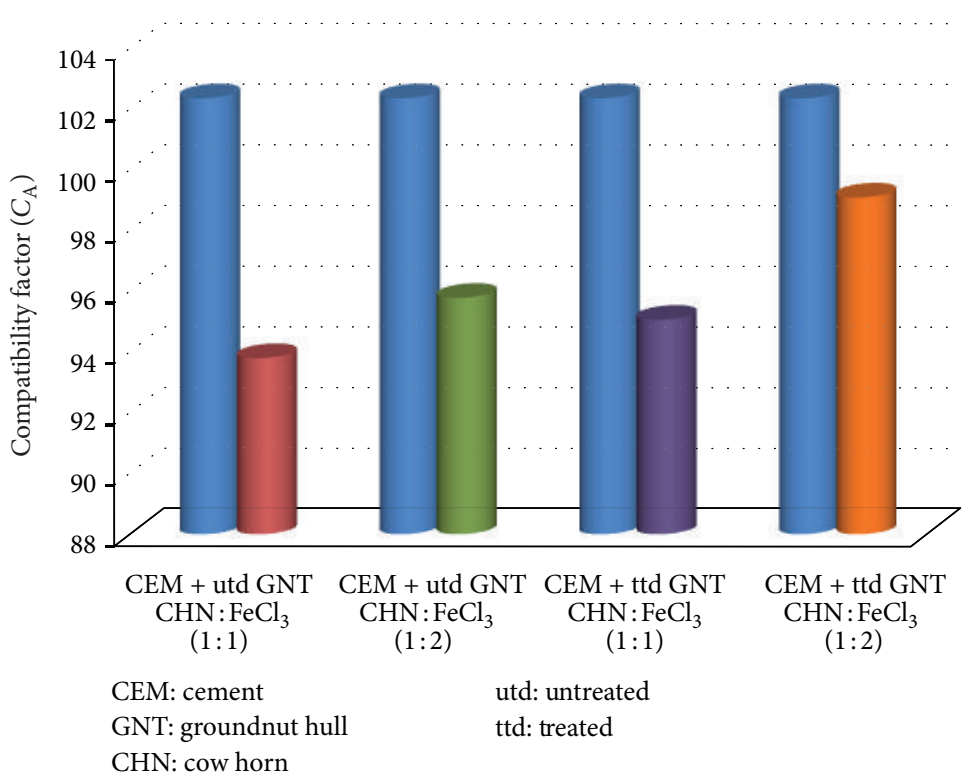

FiguRE 5: Effect of the $\mathrm{FeCl}_{3}$ and cow horn mixture at different ratios on the compatibility factors of the cement and groundnut hull particles.

More bond formations were assumed at the $\mathrm{C}=\mathrm{O}$ and $\mathrm{C}-\mathrm{O}$ functional groups due to lower shift observed when $1 \%$ of the cow horn sample (based on the weight of cement) was added to the groundnut-cement mixture. There was a shift to lower band from $1648 \mathrm{~cm}^{-1}$ for the groundnut hull to $1546 \mathrm{~cm}^{-1}$ for the (hot-water-treated groundnutcement mixture $+1 \%$ cow horn sample), which showed coordination through the $\mathrm{C}=\mathrm{O}$ functional group. Bonds were also formed through the $\mathrm{C}-\mathrm{O}$ of esters or ethers due to the lower shift experienced for the bands of the (untreated) and (hot-water-treated groundnut-cement $+2 \%$ cow horn) and (untreated) and (hot-water-treated groundnut-cement $+3 \%$ cow horn) which gave $1070 \mathrm{~cm}^{-1}, 1104 \mathrm{~cm}^{-1}, 1113 \mathrm{~cm}^{-1}$, and $1104 \mathrm{~cm}^{-1}$, respectively, and compared with the $1271 \mathrm{~cm}^{-1}$ frequency of the groundnut hull. The absence of absorption bands around $1230 \mathrm{~cm}^{-1}$ showed the consumption of phenolic hydroxyl in the C-O bond formation [30].

On the addition of iron (III) chloride $\left(\mathrm{FeCl}_{3}\right)$, lower shifts were observed when $3413 \mathrm{~cm}^{-1}$ for groundnut hull was compared with the (untreated groundnut hull sample + $1 \%$ cow horn $+1 \% \mathrm{Fe}^{3+}$ ), (hot-water treated sample $+1 \%$ cow horn $+1 \% \mathrm{Fe}^{3+}$ ), (untreated sample $+1 \%$ cow horn $+2 \% \mathrm{Fe}^{3+}$ ), (hot-water treated sample $+2 \%$ cow horn + $1 \% \mathrm{Fe}^{3+}$ ) which give $3356 \mathrm{~cm}^{-1}, 3331 \mathrm{~cm}^{-1}, 3362 \mathrm{~cm}^{-1}$, and $3246 \mathrm{~cm}^{-1}$, respectively. This indicated bond formation either through the $\mathrm{OH}$ or the $\mathrm{N}-\mathrm{H}$ groups. A lower shift was also observed for C-O groups of esters or ethers from $1271 \mathrm{~cm}^{-1}$ for groundnut hull to $1122 \mathrm{~cm}^{-1}, 1125 \mathrm{~cm}^{-1}$, and $1052 \mathrm{~cm}^{-1}$ for the (untreated sample $+1 \%$ cow horn $+1 \% \mathrm{Fe}^{3+}$ ), (hotwater-treated sample $+1 \%$ cow horn $+1 \% \mathrm{Fe}^{3+}$ ) and (treated sample $+2 \%$ cow horn $+1 \% \mathrm{Fe}^{3+}$ ), respectively.

Higher absorption bands were observed with composites containing more than $2 \%$ of the additives leading to the weakening of the bands as suggested by Semple et al. [31].

With $\mathrm{FeCl}_{3}$ and $\mathrm{CaCl}_{2}$, on their spectra data, some differences were observed in their shift. More bond is to be formed with $\mathrm{Fe}^{3+}$ because of the available d-orbital leading to a better tendency to form more bonds than $\mathrm{Ca}^{2+}$, even though calcium can expand its octet in to the d-orbital but this is still limited. This great difference in the shift should explain the difference in the bonding with $\mathrm{Fe}^{3+}$ and $\mathrm{Ca}^{2+}$.

Generally, it was observed that the bonding in the composites was formed through the hydroxyl $(\mathrm{OH})$, carbonyl $(\mathrm{C}=\mathrm{O})$, esters or ethers $(\mathrm{C}-\mathrm{O})$, and amide $(\mathrm{N}-\mathrm{H})$.

\section{Conclusion}

From the results obtained, it can be concluded that both the groundnut hull and the cow horn samples are appropriate for the production of the particleboards since all the $C_{A}$ values obtained from hydration experiments were greater than $60 \%$. However, the cow horn was found to be a good substitute for the synthetic chemical additives which are becoming more expensive coupled with their doubtful state of purity. Also, being a renewable natural resource, it can be used in a major or mass production of particleboards with limited or no health hazard usually associated with synthetic chemical additives and binders.

Setting of cement with the groundnut hull sample was enhanced by the hot-water-extraction pretreatments while the formation of bonds was found to be through hydroxyl $(-\mathrm{OH})$, carbonyl $(\mathrm{C}=\mathrm{O})$, esters or ethers $(\mathrm{C}-\mathrm{O})$, and amide $(\mathrm{N}-\mathrm{H})$ functional groups. Better results were obtained when the groundnut hulls samples and the cow horn particles were mixed at different ratios due to their complementing nature while transition metal additives such as $\mathrm{FeCl}_{3}$ are better stabilizers and multiple bond formers through chelation than the common representative metals such as calcium.

Storage over a period of time also gave a better compatibility of the groundnut hull sample with cement even in the absence of hot-water pretreatments and chemical additives making it an important factor in the reduction of cost and 
the production of an almost chemical-free cement-bonded particleboards.

\section{References}

[1] P. A. Copper, J. J. Balatinecz, and S. Steren, Agricultural waste materials for composites: A Canadian reality, 2005, http://www.calrecycle.ca.gov/Organic/Conversion.

[2] S. L. Sauter, "Developing composites from wheat straw" in Proceedings of 30th International Particleboard/Composite Materials Symposium, M. P. Wolcott, Ed., pp. 197-204, Washington State University, Pullman, Wash, USA, 1996.

[3] H. Shorma and T. D. Daten, "The manufacture of particleboard from wheat straw," in Proceedings of 30th International Particleboard/Composite Material Symposium, M. P. Wolcott, Ed., pp. 191-196, Pullman, Wass, USA, 1996.

[4] H. Deleener and H. Dupriez, Agriculture in African Rural Communities, Macmillan Publisher, London, UK, 1988.

[5] A. Ramirez-Coretti, C. A. Eckelman, and R. W. Wolfe, "Inorganic-bonded composite wood panel systems for lowcost housing: a central American perspective," Forest Products Journal, vol. 48, no. 4, pp. 62-68, 1998.

[6] A. D. Hofstrand, A. A. Moslemi, and J. F. Garcia, "Curing characteristics of wood particles for 9 northern Rocky Mountian species mixed with Portland cement," Forest Products Journal, vol. 34, no. 2, pp. 57-61, 1984.

[7] K. E. Semple and P. D. Evans, "Screeing inorganic additives for ameliorating the inhibition of hydration of Portland cemnet by the treatment of Acacia Mangium. Wood cement composite in Acia- Pacific Region," in Proceedings of Workshop Held at Rydges Hotel, Camberra, Australia, 2002.

[8] J. D. Lee, Concise Inorganic Chemistry, Blackwell Science, Osney Mead, UK, 1996.

[9] M. Hachmi, A. A. Moslemi, and A. G. Campbell, "A new technique to classify the compatibility of wood with cement," Wood Science and Technology, vol. 24, no. 4, pp. 345-354, 1990.

[10] M. H. Hachmi and A. A. Moslemi, "Correlation between woodcement compatibility and wood extractives," Forest Products Journal, vol. 39, no. 6, pp. 55-58, 1989.

[11] R. C. Weatherwax and H. Tarkow, "Effect of wood on the setting of Portland cement," Forest Product Journal, vol. 14, no. 12, pp. 567-570, 1964.

[12] W. Sha, E. A. O’Neill, and Z. Guo, "Differential scanning calorimetry study of ordinary Portland cement," Cement and Concrete Research, vol. 29, no. 9, pp. 1487-1489, 1999.

[13] M. M. Alberto, E. Mougel, and A. Zoulalian, "Compatibility of some tropical hardwoods species with Portland cement using isothermal calorimetry," Forest Products Journal, vol. 50, no. 9, pp. 83-88, 2000.

[14] AOAC, Offical Methods of Analysis, Washington DC, USA, 1984.

[15] N. R. Farnsworth, "Biological and phytochemical screening of plants," Journal of Pharmaceutical Sciences, vol. 55, no. 3, pp. 225-276, 1966.

[16] M. Simatupang, "The water requirement of manufactured cement-bonded particleboard," Holz als Roh-und Werkstoff, vol. 37, pp. 379-382, 1979.

[17] Y. Pelanpus, S. Prayoon, and J. Wong-on, "Mechanical and physcial properties of green particle board produce from corncob and starch binder composite," in PSU-UNS International
Conference of Engineering and Environment ICEE, pp. 106-548, 2007.

[18] S. O. O. Badejo, "Influences of pre-treatment temperature and additive concentration on the properties of cementbonded particleboard from plantation-grown tropical hardwoods," Tropical Science, vol. 29, pp. 285-296, 1989.

[19] ASBMR. American Society for Bones and Minerals Research: Project of Education Committee, 2007.

[20] A. A. Moslemi, J. F. Gracia, and A. D. Hofstrand, "Effect of various treatments of additives on wood-Portland cementwater system," Wood Fibre Science, vol. 15, pp. 164-176, 1983.

[21] A. M. Neville and J. J. Brooks, Concrete Technology, Pearson Eduction Longman Group, London, UK, 1987.

[22] A. Paul, P. Mamza, and K. Shadrach, "The mechanical properties of urea-formaldehyde particle boards," International Journal of Pure and Applied Science, vol. 2, pp. 15-21, 2008.

[23] O. A. Ogunkunle, Physico-chemical studies of composite boards from groundnut hulls and coconut husk. Nigeria [Ph.D. thesis], University of Ibadan, 2008.

[24] R. Hashim, W. N. A. W. Nadhari, O. Sulaiman et al., "Characterization of raw materials and manufactured binderless particleboard from oil palm biomass," Materials and Design, vol. 32, no. 1, pp. 246-254, 2011.

[25] Q. Xu and J. Stark, "Early hydration of ordinary Portland cement with an alkaline shotcrete accelerator," Advances in Cement Research, vol. 17, no. 1, pp. 1-8, 2005.

[26] M. Nazerian, E. Gozali, and M. D. Ghalehno, "The influence of wood extractives and additives on the hydration kinetics of cement paste and cement-bonded particleboard," Journal of Applied Sciences, vol. 11, no. 12, pp. 2186-2192, 2011.

[27] Y. M. Wei, Y. Guang Zhou, and B. Tomita, "Hydration behavior of wood cement-based composite I: evaluation of wood species effects on compatibility and strength with ordinary portland cement," Journal of Wood Science, vol. 46, no. 4, pp. 296-302, 2000.

[28] A. O. Olorunnisola and O. O. Adefisan, "Trial production and testing of cement-bonded particleboard from rattan furniture waste," Wood and Fiber Science, vol. 34, no. 1, pp. 116-124, 2002.

[29] A. M. Neville, Properties of Concrete, Pearson Education, Harlow, UK, 1999.

[30] R. T. Morrison and R. N. Boyd, Spectroscopy and Structures, Organic Chemistry, Prentice-Hall, New Jersey, NJ, USA, 6th edition, 1992.

[31] K. E. Semple, R. B. Cunningham, and P. D. Evans, "Cement hydration tests using wood flour may not predict the suitability of Acacia mangium and Eucalyptus pellita for the manufacture of wood-wool cement boards," Holzforschung, vol. 53, no. 3, pp. 327-332, 1999. 

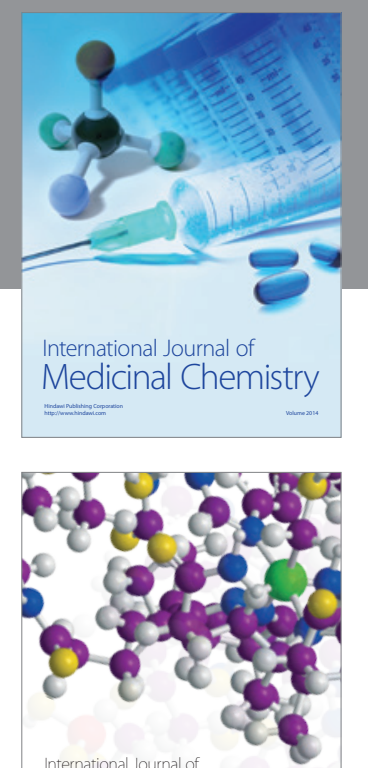

\section{Carbohydrate} Chemistry

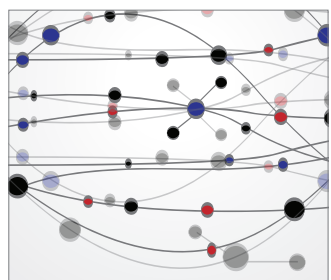

The Scientific World Journal
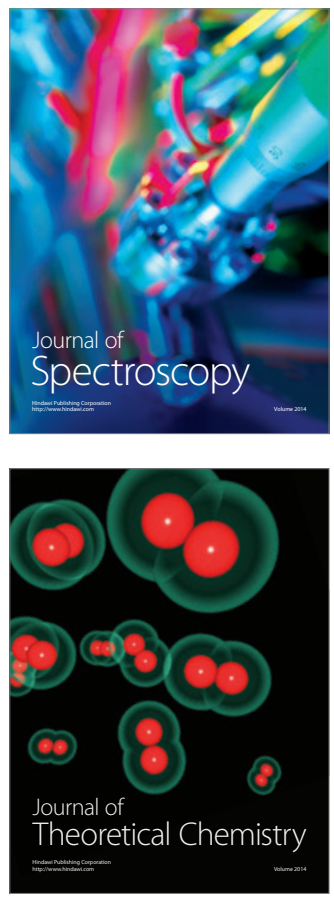
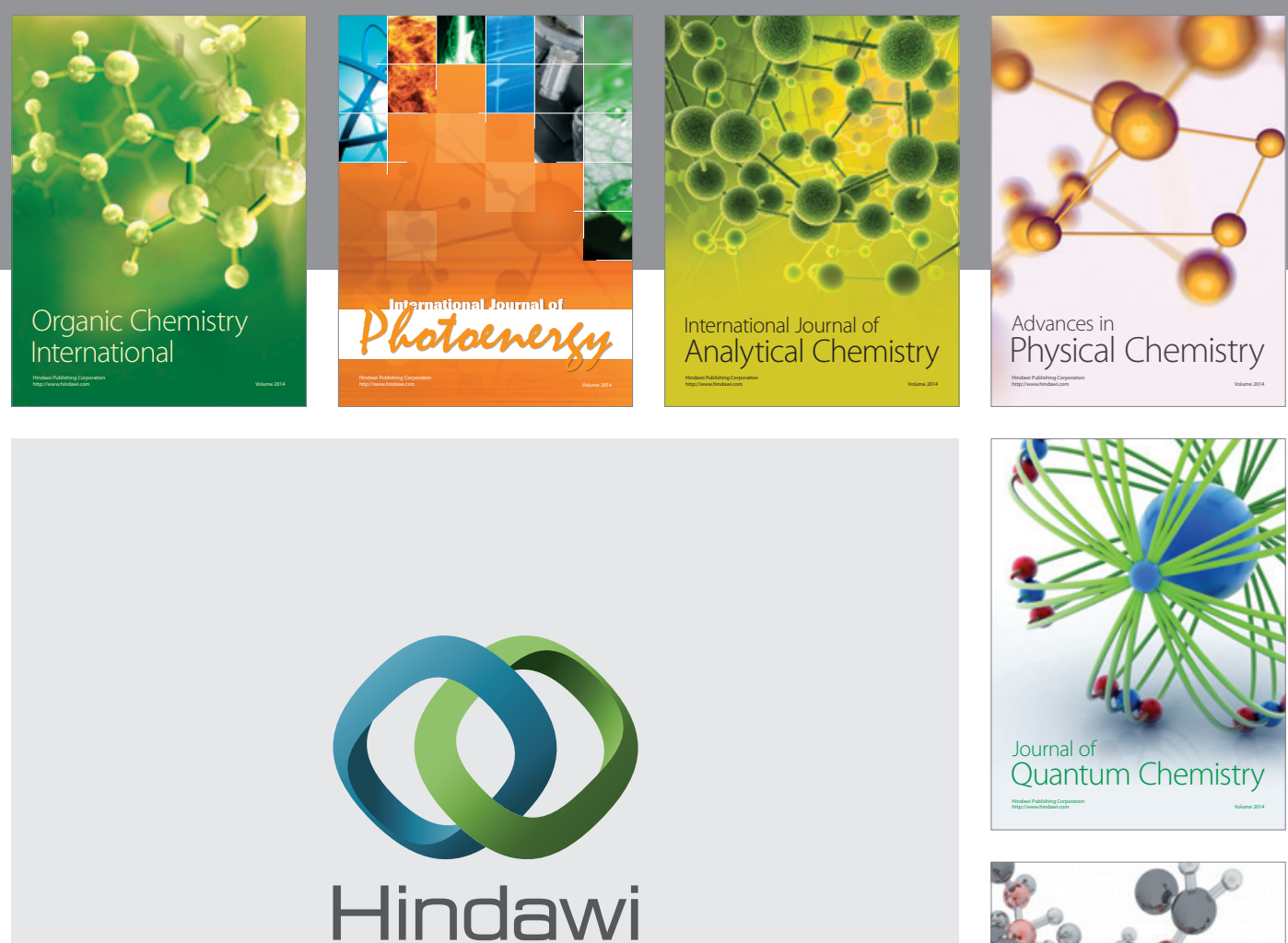

Submit your manuscripts at

http://www.hindawi.com

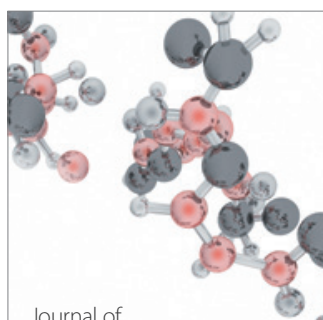

Analytical Methods

in Chemistry

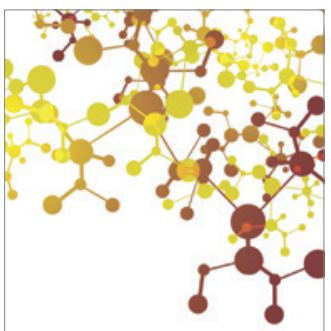

Journal of

Applied Chemistry

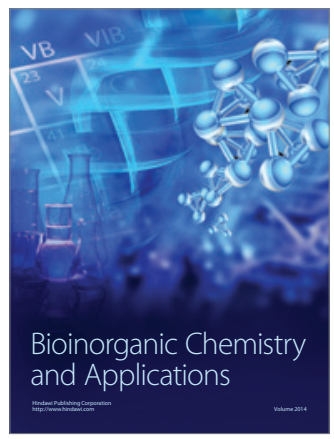

Inorganic Chemistry
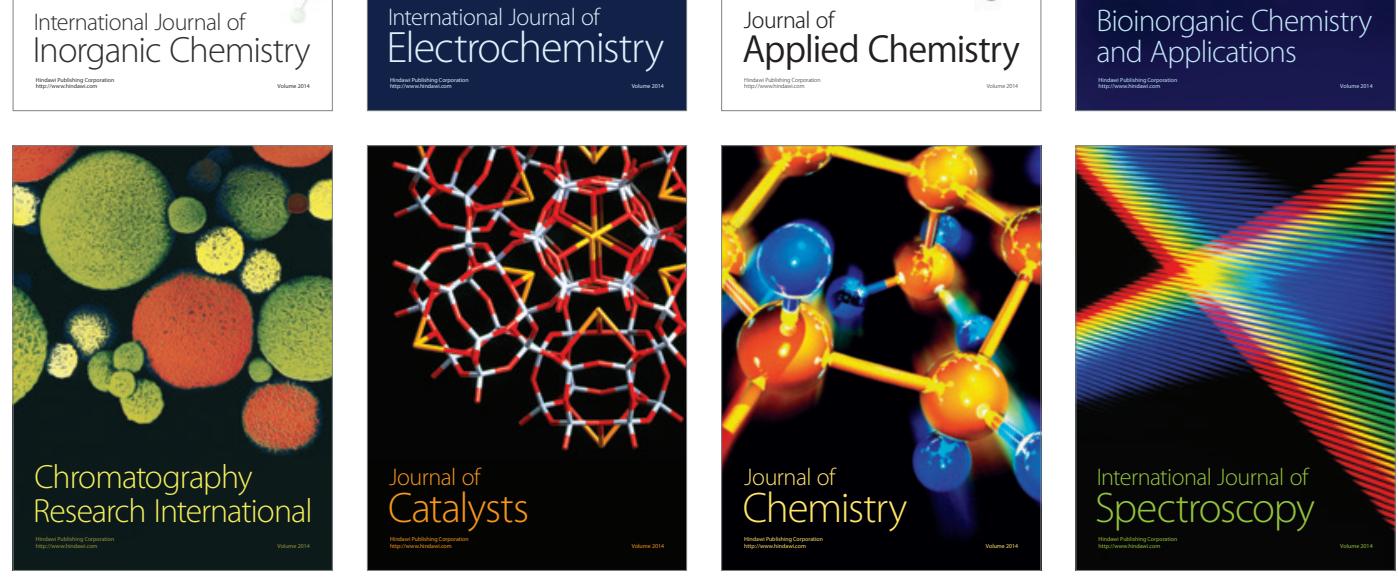